\title{
Incidence and determinants of severity of unintentional injuries among students of private schools in Dubai: a cross-sectional study
}

Ayesha Altheeb, ${ }^{7}$ Hamid Hussein, ${ }^{7}$ Waleed Al Faisal, ${ }^{1}$ Nusaiba AlBehandy, ${ }^{7}$ Nouf Alshareef ${ }^{7}$ and Ahmed Wasfy ${ }^{2}$

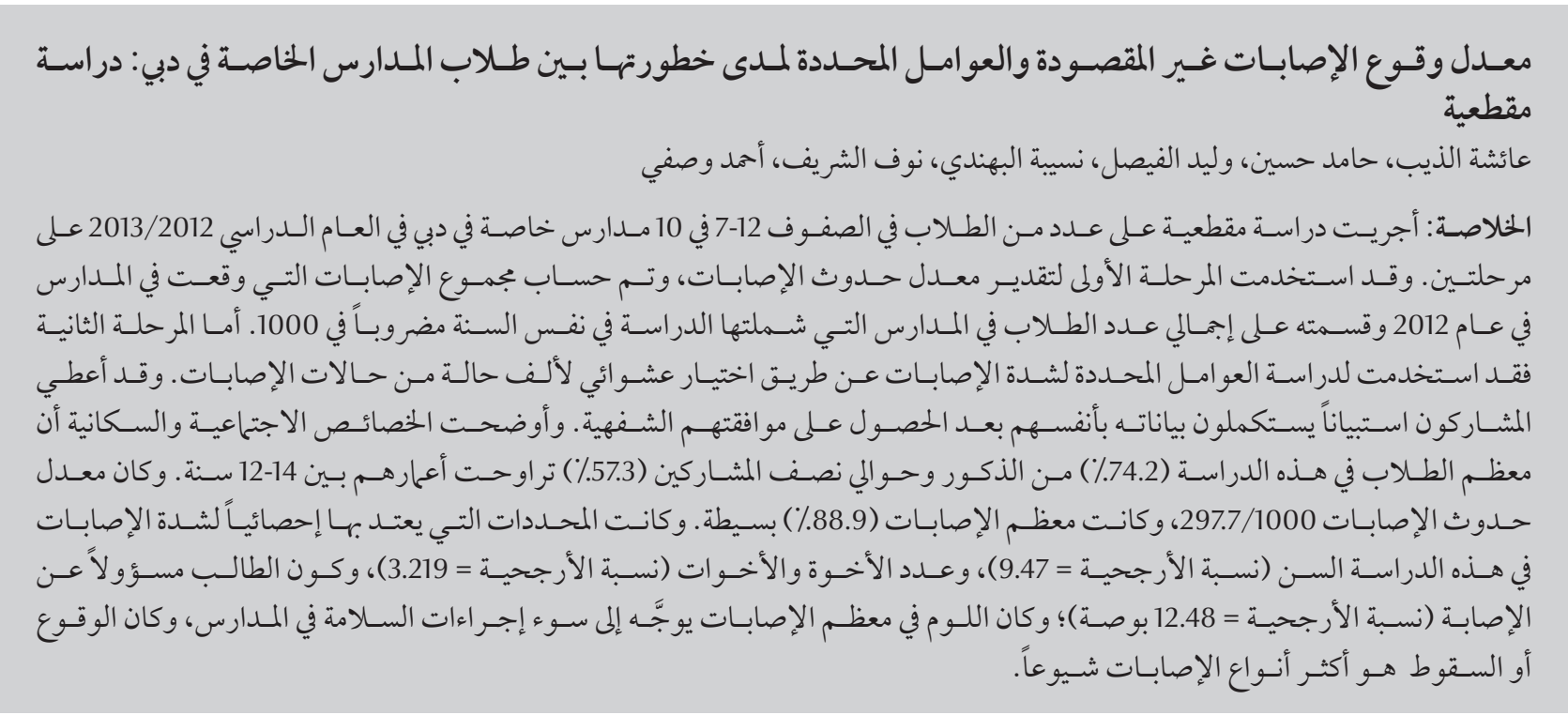

ABSTRACT A cross-sectional study was performed on a student population in grades 7-12 in 10 private schools in Dubai in the academic year 2012/13. The study was in two phases. The first was used to estimate incidence rate of injuries, where the total injuries that took place in the schools in 2012 was divided by the total student population in the studied schools in the same year multiplied by 1000 . The second was to study the determinants of severity through randomly selecting 1000 cases of injuries. A self-administered questionnaire was given to the participants after obtaining verbal consent. Sociodemographic characteristics showed that most (74.2\%) of the students in this study were male and about half (57.3\%) were aged 12-14 years. The incidence rate of injuries was 297.7/1000, and most of the injuries (88.9\%) were mild. Poor school safety was blamed for most of the injuries, and falls were the most frequent type of injury.

Incidence et déterminants de la gravité des traumatismes non intentionnels parmi les élèves d'établissements d'enseignement privé de Dubaï : étude transversale

RÉSUMÉ Une étude transversale a été menée en 2012/2013 dans 10 établissements d'enseignement privé de Dubaï, sur une population d'élèves âgés entre 10 et 17 ans. Cette étude s'est déroulée en deux phases. La première phase a permis d'estimer le taux d'incidence des traumatismes : le nombre total de traumatismes survenus dans les établissements en 2012 a été divisé par la population totale d'élèves de tous les établissements étudiés au cours de la même année puis a été multiplié par 1000. La seconde consistait à étudier les facteurs de gravité déterminants à travers une sélection aléatoire de 1000 cas de blessures. Un auto-questionnaire a été remis aux participants après l'obtention de leur consentement verbal. Les caractéristiques socio-démographiques ont montré que la majorité des élèves (74,2 \%) participant à cette étude étaient de sexe masculin et qu'environ la moitié étaient âgés de 12 à 14 ans (57,3 \%). Le taux d'incidence des traumatismes non intentionnels était de 297,7/1000, et les blessures étaient légères pour la plupart (88,9\%). Le faible niveau de sécurité dans les établissements était à l'origine de la majorité des traumatismes, et les chutes constituaient le type de traumatismes le plus fréquent.

School and Educational Institutions Health Unit, Health Affairs Department, Primary Health Care Services Sector, Dubai Health Authority, Dubai. 2 Staff Development, Health Centres Department, Primary Health Care Services Sector, Dubai Health Authority, Dubai, United Arab Emirates. (Correspondence to: W.AlFaissal:Wldalfaisal@gmail.com). 


\section{Introduction}

Unintentional school injuries have gained great importance in the field of public health worldwide as they affect the student population in many ways and raise medical costs. As injuries have been accepted as a preventable public health issue over the past decade, prevention strategies have been developed and consequently human death tolls have decreased accordingly in some countries (1). WHO issued a report showing that unintentional injuries were responsible for 3.9 million deaths and over 138 million disability-adjusted life years in 2004, with over $90 \%$ of them in low and middle income countries (LMIC) (2).

Child injuries are a problem of growing concern globally; hundreds of thousands of children die every year due to violence or injury, and millions suffer from non-fatal injuries (3). Childhood injuries along with violence are the major killers of children throughout the world, responsible for 950000 deaths annually in children and young adults younger than 18 years (2). UNICEF, in cooperation with $\mathrm{WHO}$, issued a report in 2008 on child injury prevention. One of its aims was to raise awareness about the magnitude, risk factor and impact of childhood injuries worldwide. Unintentional injuries account for $90 \%$ of deaths among children and adults less than 18 years (3). Despite this fact, the actual statistics on childhood injuries are partial and fragmented as many injuries go unreported, so the real burden of injuries in children is underestimated (4). This is combined with the impact of disproportionately early mortality, the need for critical and costly medical care, and the risk for extended periods of disability.

Injuries are linked to to the activities practiced by students, conditions of those students, and environment surrounding them as well as associated with certain individual characteristics such as age, sex, physical ability, lack of knowledge, personality, behaviour and family characteristics. Smoking, alcohol use, health status and sleep disorders are known to affect physical and mental abilities and increase the risk of injury in adults, and these factors may also lead to school injuries (5). The increased risk may also be due to conditions for which youngsters are taking medication. School achievement may also be associated with injuries because it may reflect the student's predeliction for certain school activities. Knowledge of the role of these factors may be useful for injury prevention and for school physicians, parents and school staff to raise student awareness of the risks and to find remedial measures (5). The Centers for Disease Control in the US has established several guidelines for safety in the school environment that help reduce the incidence school injuries (6). Some of these are social environment safety, physical environment safety, health education programmes, physical education and activity programmes, provision of proper health services, crisis response systems, family and community involvement and staff development. About $10 \%-25 \%$ of child and adolescent injuries occur in a school environment. Approximately 4 million children and adolescents are injured at school each year in the US (6). Despite this fact, most of these injuries are minor compared to those occurring at home (6). One of the studies concluded that $80 \%$ of elementary-school children had visited a school nurse for injury-related complaints (7).

\section{Objectives}

To obtain estimates of incidence of unintentional injuries among schoolchildren in private Dubai schools and identify their epidemiological features and severity determinants. Private schools were chosen because they compose the majority of schools in Dubai.

\section{Methodology}

A cross-sectional design was used to study unintentional injuries in Dubai's private schools among students in grades 7-12 (both males and females) in the academic year 2012-13. The study was conducted in two phases. The first estimated the incidence rate of injuries; the total injuries that took place in the schools in 2012 was divided by the total student population in the studied schools in the same year multiplied by 1000, The second phase was to study the determinants of severity through randomly selecting 1000 cases of injuries out of the total numbers of injuries.

A complete list of private schools was obtained from Dubai's Knowledge and Human Development Authority (KHDA). Dubai has 148 private schools. Five schools were randomly selected from Deira and five from Bur Dubai, the two main districts of Dubai. Sample size was calculated using computer program EPI-Info version 6.04, and based on the total number of private school students in Dubai, which was 207500 , percentage of injuries of $50 \%$, 3\% precision, 1.5 design effects and $95 \%$ confidence interval. The minimal sample size was 1000 students. Multistage stratified random sampling with proportional allocation was carried out.

\section{Inclusion criteria}

1. Students in Dubai private schools at preparatory and secondary levels (grades 7-12).

2. Students must have an injury that is spontaneous and not related to violence.

\section{Exclusion criteria}

1. Incomplete records (inuries not mentioned).

2. Students with injuries due to violence in schools.

A reportable injury is defined as an injury meeting at least one of the following criteria: an injury for which the 
student received medical treatment at the school nurse's office or received medical care from a doctor at a hospital or a private medical office; an injury for which the student received first aid from his/her schoolmates, teachers or parents; or an injury that was not treated but caused the student to miss a half day or more of school or regular activities (8).

The data were collected from students by a pilot study-tested selfadministered questionnaire composed of 32 items. The questionnaire was adopted and modified from a validated and reliable questionnaire composed of 32 items from a study held in China (8). This study was reliable and valid with Cronbach's a coefficient of reliability of 0.78 . The questionnaire comprised several sections about sociodemographic data, lifestyle behaviour and injury status. The English questionnaire was translated into Arabic by the authors and reviewed by community medicine consultants to ensure validity and reliability.

Mild and moderate injuries are defined as injuries treated within the school either by a fellow student, a teacher or the school nurse or doctor (9).

A pilot study was conducted in one randomly selected school in Dubai. One class from each grade was selected randomly, and the survey was distributed among them. There were about 50 students in the pilot study. Following this study some modifications were done to the questionnaire and information obtained about research feasibility, logistical barriers and some school-related obstacles.

The data were collected from students in schools within their classes during official study hours by self-administered questionnaire. It took half an hour of their time.

Statistical analysis was performed using SPSS program version 19. Several statistical tests were used. Frequency distribution tables were used for descriptive statistics. Chi-squared test was used for testing the association between severity of injury (mild, moderate and severe) and most of the variables such as age, sex, nationality, parent's educational level, family income). Kolmogrov-Smirnov goodness-of-fit test was used to test the normality of data. Binary regression model was adopted to analyse significant variables. Stepwise logistical regression analysis was done.

\section{Ethical considerations}

- Absolute confidentiality of the information obtained in the study was ensured throughout the research.

- Ethical approval from the ethical committee in the Dubai Health Authority (Medical Research Committee) was obtained prior to commencing the research.

- Verbal consent was obtained from each student in the study.

\section{Results}

Table 1 shows the incidence rate of unintentional injuries among Dubai private school students. It shows that the highest incidence rate among private school students was among 14-15 year olds, which was 416.9/1000, while the total incidence rate among all school students was 297.7/1000.

Figure 1 shows distribution of injuries according to cause. It demonstrates that most of the injuries were due to falls (62\%), followed by cuts (13\%), and the least involved cause was accidental poisoning (1\%). The study sample (1000 injury cases) was randomly selected from all injury cases.

According to the sociodemographic characteristics of the study sample, the students' age ranged from 12 to 17 years with mean of $13 \pm 0.687$. Male students formed $74.2 \%$ of the sample, whereas female students comprised $25.8 \%$. Regarding the nationality, $72.2 \%$ were not UAE citizens and $27.8 \%$ were UAE nationals. About $79.4 \%$ of the fathers and $67 \%$ of mothers were college graduates. The monthly income levels of families of almost half of the students was $10000-$ 20000 AED (US\$2740-5480).

Table 2 shows the distribution of injuries according to their severity. It can be seen that about $88.9 \%$ of the injuries were mild, followed by moderate injuries (9.0\%) and severe injuries 2.1\%.

Table 3 shows the association between injury severity and variables such as age, sex and nationality. Mild injuries are more common than moderate and severe. So for the $12-13$ age group, out of 573 injuries $86.2 \%$ are mild and $2.4 \%$ are severe. For the 14-15 age group, from 315 injuries, 94\% are mild and only $3 \%$ are severe. For the $16-17$ age group (112 injuries), 99\% are mild injuries and $4 \%$ are severe.

For the association between injury severity and sex, in both sexes the most dominant type of injury was mild

\begin{tabular}{|c|c|c|c|}
\hline Variable & Injuries & Population & Incidence rate/1000 \\
\hline \multicolumn{4}{|l|}{ Age (years) } \\
\hline $12-13$ & 1501 & 6000 & 250.1 \\
\hline $14-15$ & 1370 & 3286 & 416.9 \\
\hline $16-17$ & 1100 & 4050 & 271.6 \\
\hline \multicolumn{4}{|l|}{ Sex } \\
\hline Male & 3101 & 8336 & 372.0 \\
\hline Female & 870 & 5000 & 174.0 \\
\hline Total & 3971 & 13336 & 297.7 \\
\hline
\end{tabular}




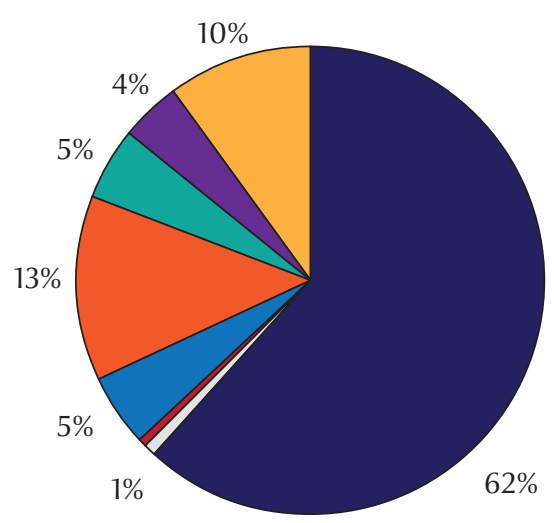

fal

accidental poisioning
accidental choke
burn
cut
electrical shock
animal/insect bite
others

Figure 1. Distribution of injuries among school students according to cause

injury-about $89.6 \%$ in males and $86.8 \%$ in females. On the other hand, severe injury was the least pronounced in both sexes, being 2.0\% in males and $2.3 \%$ in females. For nationality mild injuries are most common: $90.3 \%$ in UAE nationals and $88.4 \%$ in non-UAE nationals.

Table 4 demonstrates the association between degree of injury and parent's educational level and family income. By comparing the father's educational level with injury severity about $87.9 \%$ of 794 fathers who were college graduates had children who had mild injuries. About $94.4 \%$ of fathers with secondary-school education had children with mild injuries. Of children mildly injured, $11 \%$ and $7 \%$ of fathers were found to be illiterate or had attended primary school respectively.

With respect to mothers' educational level, it was found that the highest number of injuries (670) was in children of those mothers who had college degrees; $90.4 \%$ of these injuries were mild. Mothers who finished secondary school had 228 injured children; $84.2 \%$ of them were mild and $2.2 \%$ were severe. The least count of injuries was found for mothers who had primary education (15); all of them were mild.

Most of injured children (538) were from families that had incomes between 10000 and 20000 AED: $88.5 \%$ were mild and $2.6 \%$ were severe. There were 375 injured children of families that have income more than $20000 \mathrm{AED}$; $88 \%$ of their injuries were mild and $6 \%$ were severe.

Table 5 shows the association between injury severity and causes. It showed that poor school safety was the most frequent cause (364) of injury occurrence in the study sample. Most injuries (92.3\%) were mild. In contrast, inadequate supervision (99) was responsible for fewest injuries, most of which were mild.

Table 6 demonstrates stepwise logistic regression of some of the variables (number of siblings, age, person

\begin{tabular}{lcc}
\hline $\begin{array}{l}\text { Table 2. Frequency distribution of injuries among study sample according to their } \\
\text { severity in Dubai private schools, 2012 }\end{array}$ & \% \\
\hline Injury severity & No. & 88.9 \\
Mild & 889 & 9.0 \\
Moderate & 90 & 2.1 \\
Severe & 21 & 100 \\
\hline Total & 1000 & \\
\hline
\end{tabular}

responsible for injury) affecting the severity of unintentional injuries among the study population. It revealed that there are three significant variables: number of siblings, age and responsible person for the injury, having $p$-value of $<0.05$, which indicates that these variables are associated with the severity of unintentional injury.

\section{Discussion}

The present study aimed at estimating the incidence and determinants of unintentional school injuries among children to provide evidence-based research about this issue. This in turn allows policy-makers to carefully design appropriate prevention strategies to lower future events as well as lowering their economic burden.

$<$ body $>$ This study revealed that the incidence rate of unintentional injuries among secondary and preparatory students in Dubai for 2012 to be 297.7 per 1000. This incidence rate is higher than that reported in Oman (26.3\%) by the Oman Global School Based Student Health Survey (GSBHS) done through WHO and CDC in 2005. This figure was lower than the figures obtained in Tunisia (37.2\%) by Tunisia GSBHS in 2006, Egypt (38.5\%) by Egypt GSBHS (2006), and Yemen by Yemen GSBHS (2008) (70.4\%) (10). Among the Arab countries, UAE has a good record with respect to unintentional injuries among children. This could be due to higher school safety levels and high awareness levels of students about injuries at schools and proper health education delivered to students. It may also be explained by the process of standardization and accreditation the government imposed on all schools in Dubai.

The current study results show a relationship between injury rate and age; the youngest age group of $12-13$ years had about $57.3 \%$ of injuries compared to other age groups. This agrees with the results of a study held in France in 


\begin{tabular}{|c|c|c|c|c|}
\hline \multirow[t]{2}{*}{ Variable } & \multicolumn{3}{|c|}{ Injury severity } & \multirow{2}{*}{$\begin{array}{c}\text { Total } \\
\text { No. (\%) }\end{array}$} \\
\hline & $\begin{array}{c}\text { Mild } \\
\text { No. (\%) }\end{array}$ & $\begin{array}{c}\text { Moderate } \\
\text { No. (\%) }\end{array}$ & $\begin{array}{l}\text { Severe } \\
\text { No. (\%) }\end{array}$ & \\
\hline \multicolumn{5}{|l|}{ Sex } \\
\hline Male & $665(89.6)$ & $62(8.4)$ & $15(2.0)$ & $742(100)$ \\
\hline Female & $224(86.8)$ & $28(10.9)$ & $6(2.3)$ & $258(100)$ \\
\hline \multicolumn{5}{|c|}{ Chi-squared $=1.57, p$-value $=0.454$} \\
\hline \multicolumn{5}{|c|}{ Nationality } \\
\hline UAE & $251(90.3)$ & $24(8.6)$ & $3(1.1)$ & $278(100)$ \\
\hline Non-UAE & $638(88.4)$ & $66(9.1)$ & $18(2.5)$ & $722(100)$ \\
\hline \multicolumn{5}{|c|}{ Chi-squared $=2.052, p$-value $=0.358$} \\
\hline \multicolumn{5}{|l|}{ Age (years) } \\
\hline $12-13$ & $494(86.2)$ & 65 (11.3) & $14(2.4)$ & $573(100)$ \\
\hline $14-15$ & $296(64)$ & $16(5.1)$ & $31.0)$ & $315(100)$ \\
\hline $16-17$ & $99(88.4)$ & $9(8.0)$ & $4(3.6)$ & $112(100)$ \\
\hline \multicolumn{5}{|c|}{ Chi squared $=13.824, p$-value $=0.008$} \\
\hline Total & $889(88.9)$ & $90(9.0)$ & $21(2.1)$ & $1000(100)$ \\
\hline
\end{tabular}

$U A E=$ United Arab Emirates.

\begin{tabular}{|c|c|c|c|c|}
\hline \multirow[t]{2}{*}{ Variable } & \multicolumn{3}{|c|}{ Severity of injury } & \multirow{2}{*}{$\begin{array}{c}\text { Total } \\
\text { No. }(\%)\end{array}$} \\
\hline & $\begin{array}{c}\text { Mild } \\
\text { No. (\%) }\end{array}$ & $\begin{array}{c}\text { Moderate } \\
\text { No. (\%) }\end{array}$ & $\begin{array}{l}\text { Severe } \\
\text { No. (\%) }\end{array}$ & \\
\hline \multicolumn{5}{|l|}{ Father's education } \\
\hline Illiterate & $11(100)$ & 0 & 0 & $11(100)$ \\
\hline Primary & $7(63.6)$ & $4(36.4)$ & 0 & $11(100)$ \\
\hline Preparatory & $20(90.9)$ & $2(9.1)$ & 0 & $22(100)$ \\
\hline Secondary & $153(94.4)$ & $7(4.3)$ & $2(1.2)$ & $162(100)$ \\
\hline College/higher & 698 (87.9) & $77(9.7)$ & $19(2.4)$ & $794(100)$ \\
\hline \multicolumn{5}{|c|}{ Chi-squared $=17.938, P$-value $=0.022$} \\
\hline \multicolumn{5}{|l|}{ Mother's education } \\
\hline Illiterate & $45(91.8)$ & $2(4.08)$ & $2(4.08)$ & $49(100)$ \\
\hline Primary & $15(100)$ & 0 & 0 & $15(100)$ \\
\hline Preparatory & $31(81.6)$ & $5(13.2)$ & $2(5.3)$ & $38(100)$ \\
\hline Secondary & $192(84.2)$ & $31(13.6)$ & $5(2.2)$ & $228(100)$ \\
\hline College/higher & $606(90.4)$ & $52(7.8)$ & $12(1.8)$ & $670(100)$ \\
\hline Total & 889 (88.9) & $90(9.0)$ & $21(2.1)$ & $1000(100)$ \\
\hline \multicolumn{5}{|c|}{ Chi-squared $=18.036, P$-value $=0.054$} \\
\hline \multicolumn{5}{|c|}{ Income (AED) } \\
\hline$>20000$ & $330(88)$ & $39(10.4)$ & $6(1.6)$ & $375(100)$ \\
\hline $10000-20000$ & $476(88.5)$ & 48 (8.9) & $14(2.6)$ & $538(100)$ \\
\hline$<10000$ & $83(95.4)$ & $3(3.4)$ & $1(1.1)$ & $87(100)$ \\
\hline \multicolumn{5}{|c|}{ Chi-squared $=5.726, P$-value $=0.22$} \\
\hline Total & 889 (88.9) & $90(9.0)$ & $21(2.1)$ & $1000(100)$ \\
\hline
\end{tabular}

$A E D=$ United Arab Emirates dirham . 


\begin{tabular}{lcccc}
\hline \multicolumn{1}{l}{ Table 5 Association between causes of injury and injury severity, Dubai private schools, 2012} & & \multicolumn{1}{c}{ Total } \\
Causes of injury & Mild & Moderate & Severe & No. (\%) \\
& No. (\%) & No. (\%) & No. (\%) & $99(100)$ \\
Inadequate supervision & $83(83.8)$ & $15(15.2)$ & $1(1.0)$ & $364(100)$ \\
School safety & $336(92.3)$ & $17(4.7)$ & $11(3.0)$ & $295(100)$ \\
Bravado behaviour & $261(88.5)$ & $32(10.8)$ & $2(0.7)$ & $111(100)$ \\
Exhaustion & $90(81.1)$ & $16(14.4)$ & $5(4.5)$ & $131(100)$ \\
Not sure & $119(90.8)$ & $10(7.6)$ & $2(1.5)$ & $1000(100)$ \\
Total & $889(88.9)$ & $90(9.0)$ & $21(2.1)$ & \\
Chi-squared $=26.471$ *P-value $=0.001$ & & & & \\
\hline
\end{tabular}

2007 (5). This found that injuries were strongly associated with younger age; $18 \%$ of injuries were in the age group of 12 and younger. This shows that age is an important factor in unintentional school injuries among children. This may be due to children of this age being unable to judge the consequences of different activities they engage in with or without an adult (11). In contrast another study held in Finland on a student sample of 1135 of age group $7-15$ years, aiming at analysis of sex differences in injuries in Finland schools, showed that as the age of boys increases their risk of injury also increases. They explained this by claiming boys' risk-taking behaviour increases with age, especially at puberty (12).

The study revealed that there was no statistically significant difference between males and females ( $P$-value $=0.454)$. This may be due to the low incidence rate of the current study compared to that of other international studies. This result is different from some other studies such as the one conducted in China by Huan and colleagues about unintentional injuries at school with a sample population of 10000 students attending six primary and four middle schools selected randomly. They had a statistically significant result ( $p$-value $=$ 0.023 ) for sex being a risk factor in injury occurrence (13).

There is a significant statistical association $(P$-value $=0.022)$ between father's educational level and injury occurrence among children. It showed that fathers with a college/higher degree were most likely to have their children involved in an unintentional mild injury. This may be due to continuous business, with studies or work, or their absence from direct supervision and guidance of their children regarding avoidance of these types of injuries. This is different from a study conducted in Velestino, Greece, about incidence of unintentional injuries and risk factors in children, which showed $P$-value $=0.09$ (14). This can be explained by creation of a safer environment by more educated parents and provision of role models for safer behaviour by them as well.

As for types of injury in this study, it was seen that falls account for more than half of all types of injuries (58.2\%). This result contrasts with a study held in Ismailia in Egypt on 1303 students in grades 6-8, in which falls accounted for about $26 \%$ of injuries - the most frequent types (15). These results also were similar to a study held in Saudi Arabia about patterns of injuries among children, with a sample of 1650 aged $<18$ years old. Falls were the most common type of injuries in their study at about $40.4 \%$ (16). In our view, the school environment is a place where students can expend their full energy, and this is done by engaging in different activities such as playing, mostly in playgrounds, and the most likely type of injury to occur there is a fall.

This study also found that mostly the responsible person for causing the injury was the student himself as it was statistically significant $(P$-value $=$

$\begin{aligned} & \text { Table 6. Logistic regression of some variables affecting the severity of unintentional injuries among the study population in } \\
& \text { Dubai private schools, 2012 }\end{aligned}$
\begin{tabular}{|lcccc}
\hline Variable & B & $p$ & OR & $95 \% \mathrm{Cl}$ \\
Age (years) & -0.888 & 0.008 & 9.47 & $0.23-0.72$ \\
$12-13$ & -0.516 & 0.002 & 1.43 & $0.26-1.39$ \\
$13-14$ & 1.457 & 0.232 & 0.94 & $0.89-2.38$ \\
Sex & 0.759 & 0.132 & 3.22 & $0.55-1.04$ \\
Number of siblings & 0.434 & 0.086 & 12.48 & $0.28-0.68$ \\
Responsible person & & 0.000 & & \\
\hline
\end{tabular}

$O R=$ odds ratio; $95 \% \mathrm{Cl}=95 \%$ confidence intervals for $B$. 
0.000). This may be due to the aggressiveness of young people and high levels of energy in them which makes them act without thinking of the consequences to their health. This finding was similar to that of the French study mentioned above (5). This found that students who were less calm and easily irritated suffered more injuries. The researchers in that study explained this by personality traits, which they clearly stated in their results; this may be the case here as well.

The current study showed that most of the injuries occurred due to poor school safety, as it accounted for about 364 of the 1000 injuries $(P$-value $=$ 0.001 ). This may be because some of the schools did not have a playground safe for performing physical activities. Some schools had poorly constructed stairs that gave rise to falls. This was different from the causes listed in the French study (5). This concluded that exhaustion was the main cause of school injuries in their sample population, which in turn led to lack of attention, lack of risk of awareness, lack of experience, nervous irritation and weaker physical abilities.

Among the positive findings in the current study was association of injuries with the students' study grade ( $P$-value $=0.048$ ) with most of the injuries occurring in students with grades of $85 \%$ or higher. This may be because more intelligent pupils involve themselves in more than one activity at a time. This observation disagreed with the French study, which showed that poorer average school performance was a risk factor for frequent injuries (6).

Regarding the logistic regression, a binary regression model was used to analyse significant variables. It showed that age of the student, number of siblings and person responsible for the injury were associated with injury incidence. Students in age group 12-13 years or having three or four siblings were more likely to suffer unintentional injuries. These results were different from the study in China by Jiang et al. (17). This study was conducted on a sample of 1944 students in high schools. In their logistic regression they found that student sex and mother's health status were associated with injuries.

\section{Limitations}

The study was conducted only in private schools because they compose the bulk of schools in Dubai (90\%). The School Health Unit in Dubai Health Authority is responsible only for private schools. Cooperation will be built in the future with the Ministry of Health to study the public schools and compare their results with the findings of the private schools. Evidence provided by a cross-sectional study is not strong enough to draw any causal inferences, so further prospective cohort studies must be conducted. Not all possible variables were analysed (e.g. lifestyle), and so there will be a need for further investigation and analysis.

\section{Conclusion and recommendations}

Injury incidence is a problem. Unintentional school injury severity is directly associated with a number of factors: student's age, student behaviour such as aggressiveness or calmness, parents' educational level, family income, student's academic performance level, school environment safety measures, and school supervision and awareness procedures. School-related unintentional injuries are an important issue that must be considered carefully, especially among preparatory grade students, as this age group has unique lifestyle characteristics.

Decision-makers should prompt researchers to study and design proper solutions. Prevention of school injuries should become a national priority as they are ofhigh incidence. A surveillance system, policies, guidelines and standards for unintentional injury prevention should be developed. Schools, which are an important part of prevention of unintentional injuries, should pay attention to: application of safety measures to activity areas such as playgrounds and gymnasiums, removal of unsafe equipment, activation of supervision system, increasing awareness activities (health education). Parents, students and other family members should be involved in all aspects of school life including planning and implementing unintentional injury prevention programmes and policies. Community partnerships and a multi-aspect approach to properly addressing injuries using different strategies should be established. Safety and injury prevention legislation should be reviewed.

\section{Funding: None.}

Competing interests: None declared.

\section{References}

1. The injury chart book. Geneva: World Health Organization; 2002. (http://whqlibdoc.who.int/publications/924156220X. pdf, accessed 1 May 2016).

2. The global burden of disease: 2004 update. Geneva: World Health Organization; 2008. (http://www.who.int/healthinfo/ global_burden_disease/2004_report_update/en/index. $\mathrm{html}$, accessed 1 May 2016).
3. World report on child injury prevention. New York: UNICEF; 2008(http://www.unicef.org/eapro/World_report.pdf, accessed 1 May 2016).

4. Child and adolescent health. Cairo: World Health Organization Regional Office for the Eastern Mediterranean. Available at: http://www.emro.who.int/cah/research.htm\#Section1. Accessed 21 May 2012. 
5. Chau N, Predine R, Benamghar L, Michaely JP, Choquet $M$, Predine E. Determinants of school injury proneness in adolescents: a prospective study. Public Health. 2008 Aug;122(8):801-8. PMID:18295288

6. Zaloshnja E, Miller TR, Lawrence BA, Romano E. The costs of unintentional home injuries. Am J Prev Med. 2005 Jan;28(1):8894. PMID:15626562

7. Guidelines for school health programs to prevent unintentional injuries and violence: summary. Atlanta: Centers for Disease Control and Prevention, (https://stacks.cdc.gov/view/ cdc/21064, accessed 1 May 2016).

8. Shi H, Yang X, Huang C, Zhou Z, Zhou Q, Chu M. Status and risk factors of unintentional injuries among Chinese undergraduates: a cross-sectional study. BMC Public Health. 201107 05;11:531. PMID:21729294

9. Robinson TN, Wilde ML, Navracruz LC, Haydel KF, Varady A. Effects of reducing children's television and video game use on aggressive behavior: a randomized controlled trial. Arch Pediatr Adolesc Med. 2001 Jan;155(1):17-23. PMID:11177057

10. Saran NA. Non-intentional injuries in adolescents and youth: facts and figures. Bahrain Med Bull. 2012;34:1.

11. National Center for Injury Prevention and Control. Injury fact book 2001-2002. Atlanta: Centers for Disease Control and Prevention; 2001.
12. Salminen $S$, Lounamaa A, Kurenniemi M. Gender and injury in Finnish comprehensive schools. Accid Anal Prev. 2008 Jul;40(4):1267-72. PMID:18606255

13. Sun YH, Yu IT, Wong TW, Zhang Y, Fan YP, Guo SQ. Unintentional injuries at school in China-patterns and risk factors. Accid Anal Prev. 2006 Jan;38(1):208-14. PMID:16236234

14. Petridou E, Anastasiou A, Katsiardanis K, Dessypris N, Spyridopoulos T, Trichopoulos D. A prospective population based study of childhood injuries: the Velestino town study. Eur J Public Health. 2005 Feb;15(1):9-14. PMID:15788797

15. Hesham E, Fatma H, Suzan G. Cross-sectional study of injuries among school children in Ismailia Governorate, Egypt. Injury prevention journal, 2012; 18:A117.

16. Gad A, AlEid R, AlAnsary S, Saeed A, Kabbash A. Pattern of injuries among children and adolescents in Riyadh, Saudi Arabia: a household survey. J Trop Pediatr. 2011 Jun;57(3):179-84. PMID:20724436

17. Jiang X, Zhang Y, Wang Y, Wang B, Xu Y, Shang L. An analysis of 6215 hospitalized unintentional injuries among children aged 0-14 in northwest China. Accid Anal Prev. 2010 Jan;42(1):320-6. PMID:19887174 